\title{
PRKAR1A Gene Mutation
}

National Cancer Institute

\section{Source}

National Cancer Institute. PRKAR1A Gene Mutation. NCI Thesaurus. Code C129503.

A change in the nucleotide sequence of the PRKAR1A gene. 